Departamento de Fitotecnia, Universidade Federal de Pelotas (UFPel), CP 354, CEP 96010-900, Pelotas, RS, Brasil

${ }^{2}$ Instituto de Biologia, Universidade Federal do Rio Grande (FURG), Rio Grande, RS, Brasil

${ }^{3}$ Departamento de Fitotecnia, Faculdade de Agronomia Eliseu Maciel, Universidade Federal de Pelotas (UFPel), Pelotas, RS, Brasil

* autor correspondente $\boldsymbol{\nabla}$ felipe.koch@hotmail.com

\section{Expressão isoenzimática e do vigor de sementes de centeio sob efeito da restrição hídrica}

\author{
Isoenzyme expression and the seed vigor of rye under effect \\ the water restriction
}

Tiago Pedó ${ }^{1 *}$, Felipe Koch ${ }^{1}$, Alexandre Gazolla Neto ${ }^{1}$, Danielli Olsen', Maria Alice da Silva de Castro ${ }^{1}$, Emanuela Garbin Martinazzo ${ }^{2}$, Tiago Zanatta Aumonde ${ }^{3}$, Francisco Amaral Villela ${ }^{3}$
RESUMO: Este trabalho objetivou avaliar o efeito da restrição hídrica sobre a expressão isoenzimática e o desempenho de sementes e plântulas de centeio. Para simulação do déficit hídrico foram empregados os potenciais osmóticos 0,$0 ;-0,25 ;-0,50$ e - $0,75 \mathrm{MPa}$. Foram avaliados a germinação, primeira contagem de germinação, índice de velocidade de germinação, comprimento e massa seca de parte área e de raiz, a expressão das isoenzimas peroxidase, malato-desidrogenase, glutamato-oxalacetato-transaminase, esterase e fosfatase ácida. A germinação, a primeira contagem, o índice de velocidade de germinação, o comprimento e a massa seca de parte aérea e de raiz foram reduzidos quando ocorreu a diminuição do potencial osmótico. A expressão e a intensidade de bandas das isoenzimas peroxidase, malato-desidrogenase, glutamato oxalacetato transaminase, esterase e fosfatase ácida foram alterados de forma distinta pelos potenciais osmóticos. A restrição hídrica afeta negativamente o desempenho de sementes e plântulas de centeio. Potenciais osmóticos inferiores a $-0,25 \mathrm{MPa}$ reduzem drasticamente a germinação, o vigor e o crescimento inicial de plântulas, que mantém potencial relação com a alteração da expressão de diferentes sistemas isoenzimáticos.

PALAVRAS-CHAVE: Crescimento, enzimas, estresse hídrico, performance, Secale cereale L.
ABSTRACT: This work aimed to evaluate the and performance of seeds and seedlings of rye. For simulation of water deficit were employed osmotic potential 0,0; -0,25; -0,50 e -0,75 MPa. Germination, first counting of germination, germination speed index, length and dry mass of seedlings shoot and roots were evaluated and total expression of isoenzymes peroxidase, malate dehydrogenase, glutamate-oxalacetate transaminase, esterase and acid phosphatase. The germination, first counting of germination, germination speed index, length and dry mass of seedlings shoot and roots were reduced by decreased the osmotic potential. The expression and intensity of bands isoenzymes peroxidase, malate dehydrogenase, glutamate-oxalacetate dehydrogenase, esterase and acid phosphatase were altered differently by osmotic potential. Water restriction adversely affects the performance of seeds and seedlings of rye. Osmotic potentials below -0.25 MPa drastically reduce germination, vigor and early growth of seedlings, which maintaining potential relationship to altered expression of different isozyme systems.

KEYWORDS: Growth, enzymes, water estress, performance, Secale cereale $L$. effect of water restriction on isozyme expression

\section{Introdução}

O centeio é uma cultura de inverno que, comparada aos demais cereais de estação fria, apresenta elevada rusticidade e adaptação a condições edafoclimáticas adversas. Espécie cuja área cultivada atinge cerca de 1,7 mil hectares, com produção média de 2,9 mil toneladas e produtividade média 
no Brasil, na safra de 2013/2014, de 1,7 toneladas por hectare (COMPANHIA..., 2016).

A disponibilidade de água é uma das principais limitações para o cultivo, por afetar o adequado estabelecimento das plantas em campo, por interferir na relação hídrica entre planta, solo e atmosfera e alterar seu metabolismo modificando diversos processos fisiológicos, com reflexos sobre o crescimento e o desenvolvimento vegetal (NOGUEIRA; MORAES; BURITY, 2001).

A absorção de água pela semente é um processo físico-químico essencial para a retomada da atividade metabólica após a maturidade fisiológica. A água, capaz de dissolver grande quantidade de compostos, possui elevado potencial químico e desempenha papel fundamental no processo germinativo, por permitir a reidratação dos tecidos, a intensificação da atividade respiratória e demais processos metabólicos visando a síntese de novos compostos, a hidrólise e a translocação de assimilados para o embrião (PESKE; VILLELA; MENEGHELLO, 2012).

Os eventos relacionados ao processo germinativo podem ser inviabilizados por potenciais hídricos muito baixos que influenciam na absorção de água pela semente (PESKE; VILLELA; MENEGHELLO, 2012) e cada espécie apresenta um valor de potencial hídrico, abaixo do qual a germinação não ocorre (LOPES; MACEDO, 2008). Neste sentido, segundo Machado Neto et al. (2004) sementes submetidas a restrição hídrica apresentam redução na expressão do vigor.

A redução no índice de velocidade e na porcentagem de germinação são verificados em condições de déficit hídrico e demonstram redução do vigor e da viabilidade da semente. A inibição destes processos fisiológicos é atribuída à alteração da atividade e do padrão de expressão enzimática, que caso se processe inadequadamente, inviabiliza a sequência de eventos que refletem na protrusão radicular e na emergência das plântulas em campo (PESKE; VILLELA; MENEGHELLO, 2012). Neste sentido, a exposição das sementes durante o processo germinativo a condições de restrição hídrica, podem levar à elevação na produção de radicais livres, prejudicar o padrão de expressão de isoenzimas, afetar a seletividade de membranas (MALONE et al., 2007; HENNING et al., 2010), fatores que por sua vez estão ligados estreitamente a expressão do vigor das sementes.

Estudos visando simular condições de restrição hídrica, por meio de solução aquosa de polietilenoglicol, têm sido realizados para avaliar o desempenho de sementes e plântulas em condições de baixa disponibilidade hídrica. Este estresse ocasiona redução na germinação das sementes e no crescimento das plântulas (DANTAS et al., 2011), pela redução da expansão e do alongamento celular (MOTERLE et al., 2006) nesta condição.

Assim, trabalhos voltados à avaliação da restrição hídrica sob a germinação e o vigor, tem sido desenvolvidos com diversas culturas como feijão (MORAES; MENEZES; PASCUALI, 2005; CUSTÓDIO; SALOMÃO; MACHADO NETO, 2009), canola (ÁVILA et al., 2007), milho (MOTERLE et al., 2006; KAPPES et al., 2010) e soja (BRACCINI et al., 1998; MORAES; MENEZES, 2003; SILVA; RODRIGUES; VIEIRA, 2006). No entanto, para centeio, há carência de estudos relacionados à qualidade fisiológica de sementes e à expressão isoenzimática em plântulas.

Considerando a possibilidade de que sementes e plântulas de centeio possam apresentar sensibilidade ao efeito do déficit hídrico, este trabalho objetivou avaliar o efeito da restrição hídrica sobre a expressão isoenzimática e o desempenho de sementes e plântulas da referida espécie.

\section{Material e Métodos}

O trabalho foi conduzido no Laboratório de Fisiologia de Sementes do Programa de Pós-graduação em Ciência e Tecnologia de Sementes da Universidade Federal de Pelotas, situada na latitude $31^{\circ} 52^{\prime} \mathrm{S}$, longitude $52^{\circ} 21^{\prime} \mathrm{W}$ e altitude $13 \mathrm{~m}$.

Foram utilizadas sementes de centeio, cultivar BRS Serrano produzidas pela Cooperativa COTRIJUI. A amostra média foi obtida segundo Brasil (2009) e os tratamentos consistiram em quatro potenciais osmóticos $(0,0 ;-0,25 ;-0,50$ e $-0,75 \mathrm{MPa})$, estabelecidos a partir de testes preliminares por meio de soluções compostas por água destilada e diferentes concentrações de polietilenoglicol (PEG-6000), empregando-se a relação massa e volume $(\mathrm{m} / \mathrm{v})$. Para avaliação da influência do déficit hídrico sobre o desempenho fisiológico de sementes e a expressão isoenzimática em plântulas de centeio foram realizados os seguintes testes:

Teste de germinação (G): avaliada por meio de quatro amostras de quatro subamostras de 50 sementes. As sementes foram dispostas em rolos formados por três folhas de papel germitest, umedecidas com as soluções de diferentes potenciais osmóticos em quantidade equivalente a 2,5 vezes a massa do papel. Os rolos foram transferidos para câmara de germinação tipo BOD a $20^{\circ} \mathrm{C}$ e período luminoso de 12 horas. A contagem foi realizada aos sete dias após a semeadura e os resultados expressos em porcentagem de plântulas normais, conforme indicado pelas Regras de Análise de Sementes - RAS (BRASIL, 2009).

Primeira contagem da germinação (PCG): realizada conjuntamente ao teste de germinação, com avaliação aos quatro dias após a semeadura. Os resultados foram expressos em porcentagem de plântulas normais, conforme indicado pela RAS (BRASIL, 2009).

Índice de velocidade de germinação (IVG): obtido a partir de contagens diárias das sementes germinadas (protrusão radicular mínima de 3 a $4 \mathrm{~mm}$ ). As contagens foram realizadas até a obtenção do número constante de sementes germinadas. O IVG foi obtido de acordo com Nakagawa (1994).

Comprimento de parte aérea $\left(\mathrm{CP}_{A}\right)$ e de raiz de plântulas $\left(C_{R}\right)$ : avaliados por meio de quatro subamostras de 10 plântulas, ao final do teste de germinação. O comprimento de parte aérea foi obtido pela medida da distância entre a inserção da porção basal da radícula ao ápice da parte aérea, enquanto, o comprimento de raiz foi mensurado pela medida da distância entre a parte apical e basal da raiz (NAKAGAWA, 1999). Os resultados foram expressos em milímetros por órgão $\left(\mathrm{mm}\right.$ órgão $\left.\mathrm{o}^{-1}\right)$.

Massa seca parte aérea $\left(\mathrm{MS}_{\mathrm{PA}}\right)$ e de raiz das plântulas $\left(\mathbf{M S}_{\mathrm{R}}\right)$ : obtida pela aferição da massa de quatro subamostras de 10 plântulas, ao final do teste de germinação. As partes aéreas 
e raízes foram acondicionadas em envelopes de papel pardo e submetidas à secagem em estufa de ventilação forçada sob temperatura de $70{ }^{\circ} \mathrm{C}$, por 72 horas (NAKAGAWA, 1999). Os resultados foram expressos em miligramas por órgão (mg órgão ${ }^{-1}$ ).

Expressão isoenzimática: o material vegetal utilizado para a determinação das isoenzimas foi obtido pela coleta de 10 plântulas do teste de germinação, sete dias após a semeadura. A expressão das isoenzimas peroxidase, malato-desidrogenase, glutamato-oxalacetato-transaminase, esterase e fosfatase ácida foi determinada pelo sistema de eletroforese vertical em gel de poliacrilamida. Para isso, as plântulas foram maceradas separadamente em gral de porcelana, em banho de gelo. Após, $200 \mathrm{mg}$ do macerado de cada amostra foi transferido para tubos de microcentrífuga e acrescidos de solução extratora (Borato de Lítio 0,2 $\mathrm{M}$ a pH 8,3 + Tris Citrato+0,2 $\mathrm{M}$ a pH 8,3) + $0,15 \%$ de 2-mercaptoetanol) na proporção $1: 2(\mathrm{~m} / \mathrm{v})$ conforme metodologia empregada por Malone et al. (2007). A eletroforese foi realizada em géis de poliacrilamida $7 \%$, aplicando-se $20 \mu \mathrm{L}$ de cada amostra, estabelecida a partir de teste prévio. Os géis foram colocados em cubas eletroforéticas verticais mantidas em câmara fria com temperatura entre 4 e $6{ }^{\circ} \mathrm{C}$ e as migrações eletroforéticas foram realizadas com uma diferença de potencial de $10 \mathrm{~V} \mathrm{~cm}^{-1}$, até que a linha de frente formada pelo azul de bromofenol atingisse $9 \mathrm{~cm}$ do ponto de aplicação. Os sistemas de coloração utilizados foram os descritos por Scandálios (1969) e Alfenas (1998).

O delineamento experimental foi de blocos casualizados com quatro repetições. Os dados apresentaram homogeneidade da variância, não sendo transformados em arco seno. Os dados relacionados ao processo germinativo e ao crescimento inicial foram submetidos à análise de variância e se significativo a 5\%, foram ajustados por polinômios ortogonais. A interpretação dos resultados referentes às isoenzimas foi por análise visual dos géis, presença ou ausência e intensidade de expressão das bandas.

\section{Resultados e Discussão}

A partir dos resultados obtidos é possível verificar que sementes e plântulas de centeio apresentaram desempenho distinto frente às diferentes restrições hídricas simuladas por polietilenoglicol (Figuras 1 e 2).

A germinação e a primeira contagem de germinação foram alteradas pela restrição hídrica e apresentaram tendência quadrática de crescimento, com elevados coeficientes de determinação, 0,91 e 0,94 respectivamente (Figura 1a). Os pontos de máxima foram atingidos nos potenciais osmóticos de - 0,15 e $0,0 \mathrm{Mpa}$ para a germinação e primeira contagem, respectivamente. Houve redução do processo germinativo ao diminuir o potencial osmótico da solução abaixo de $-0,25 \mathrm{MPa}$ e resultados mais drásticos foram observados na primeira contagem de germinação, o que corrobora aos menores valores de IVG em tais condições (Figura 1b). Estudando a germinação e o vigor de sementes de híbridos de milho sob déficit hídrico, Kappes et al. (2010) verificaram que a germinação é reduzida ao diminuir o potencial osmótico. Resultados semelhantes foram encontrados por Silva; Rodrigues e Vieira (2006) ao estudarem o desempenho de sementes de soja sob ação de diferentes potencias osmóticos simulados por polietilenoglicol. (a)

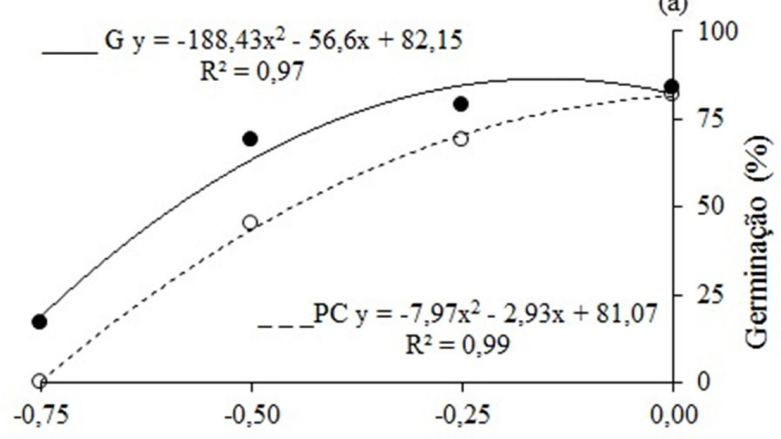

(c)

$$
\begin{aligned}
\mathrm{CP}_{\mathrm{A}} \mathrm{y}= & 4,57 \mathrm{x}^{2}-41,37 \mathrm{x}+84,14 \\
& \mathrm{R}^{2}=0,99 \\
--\_\mathrm{CP}_{\mathrm{R}} \mathrm{y}= & 0,71 \mathrm{x}^{2}-22,76 \mathrm{x}+74,87 \\
& \mathrm{R}^{2}=0,88
\end{aligned}
$$

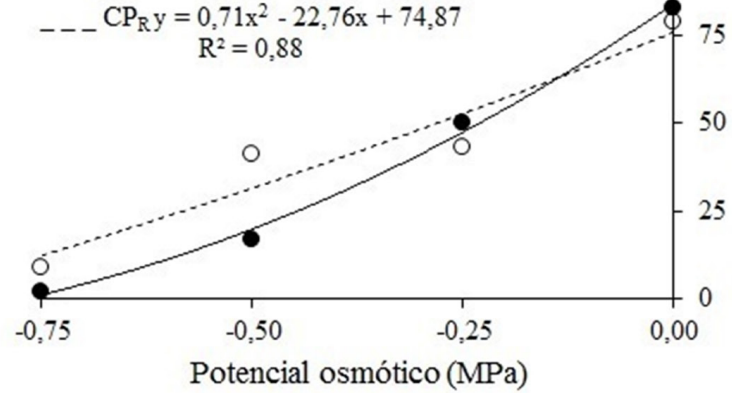

100

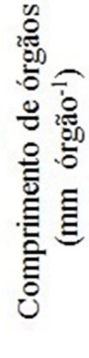

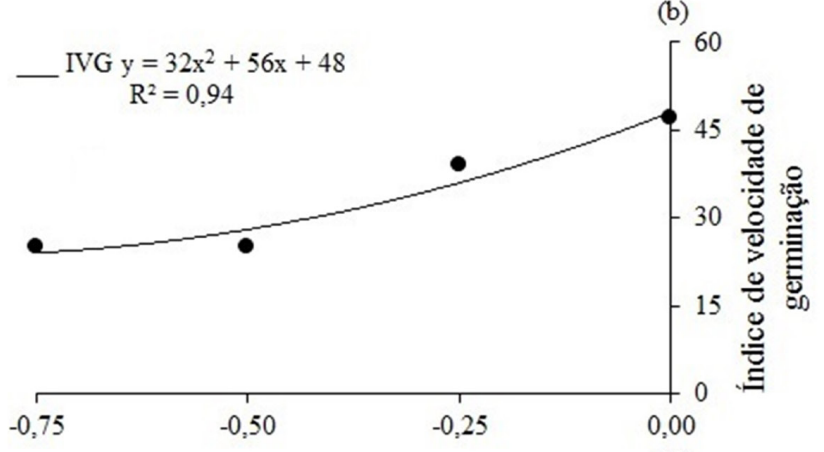

(b)

(d)

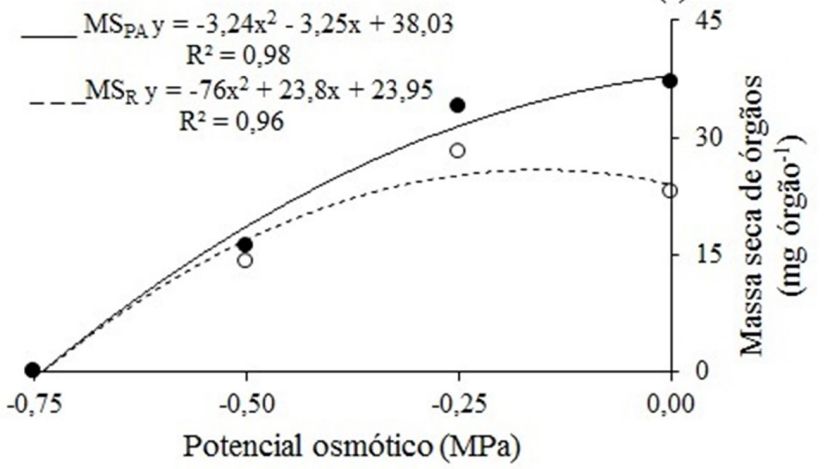

Figura 1. Germinação $(\mathrm{G})(\mathrm{a})$; índice de velocidade de germinação (IVG) (b); comprimento $\left(\mathrm{C}_{\mathrm{PA}}\right)$ (c); e massa seca de órgãos $\left(\mathrm{MS}_{\mathrm{PA}}\right)(\mathrm{d})$ de plântulas de centeio (Secale cereale L.) cultivar BRS Serrano sob restrição hídrica simulada por PEG-6000. 

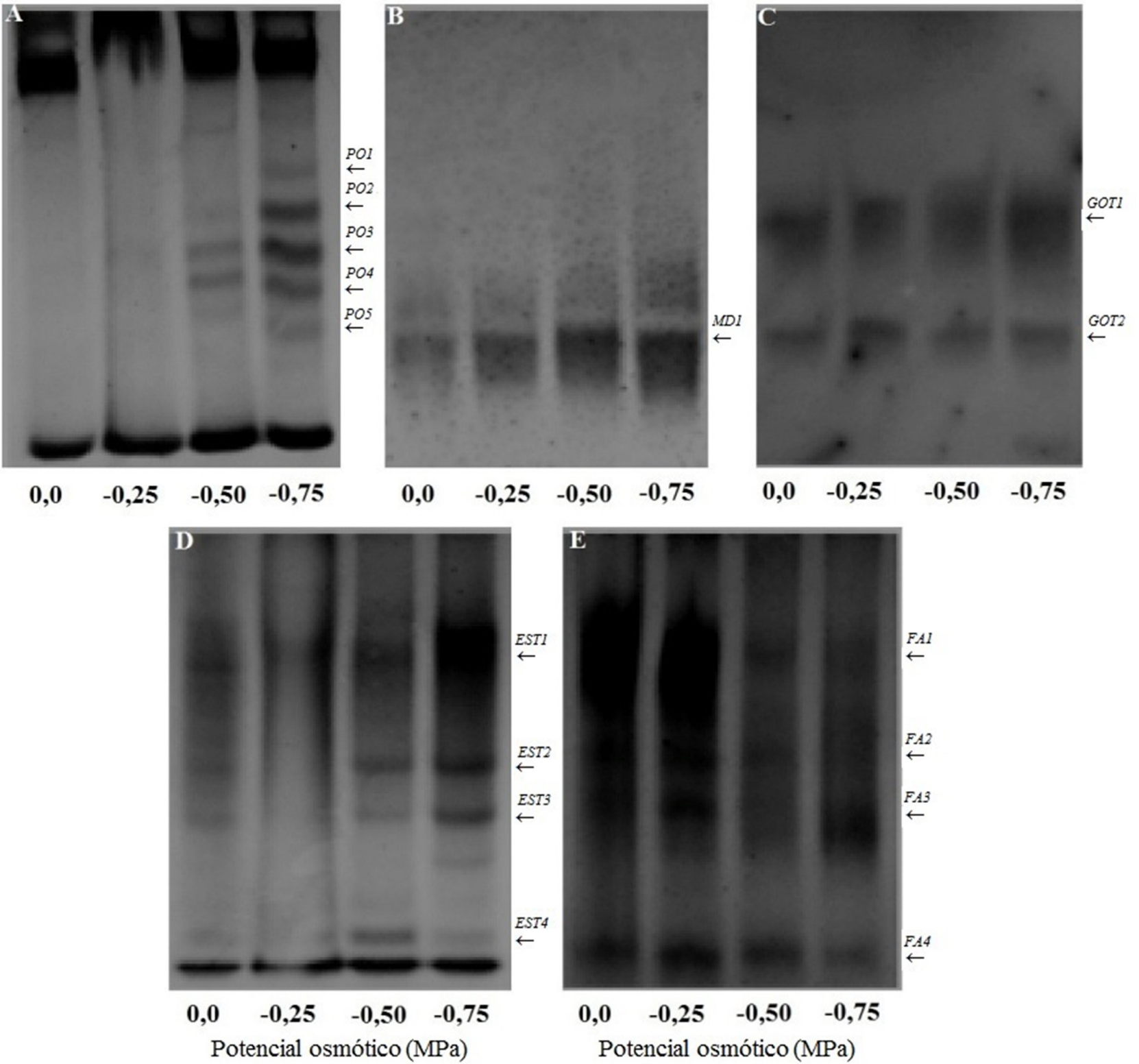

Figura 2. Expressão isoenzimática em plântulas de centeio (Secale cereale) cultivar BRS Serrano sob restrição hídrica simulada por PEG-6000, sendo: $(A)=$ peroxidase; $(B)=$ malato desidrogenase $;(C)=$ glutamato oxalacetato transaminase; $(D)=$ esterase; $(E)=$ fosfatase ácida.

A redução da germinação frente à diminuição do potencial osmótico pode estar relacionada ao efeito estressante ocasionado por radicais livres produzidos em resposta à restrição hídrica. O peróxido de hidrogênio e o íon superóxido são responsáveis pela peroxidação de lipídeos e consequentemente pela perda da capacidade seletiva e fluidez do sistema de membranas celulares. Os radicais superóxido $\left(\mathrm{O}_{2}{ }^{-}\right)$são produzidos pelo bloqueio da cadeia de transporte de elétrons conjuntamente à geração de elétrons livres ou, pela reação de transferência de elétrons da ferredoxina ao oxigênio molecular. Os radicais $\mathrm{O}_{2}^{\bullet}$, em um processo mediado pela enzima superóxido-dismutase, são convertidos em peróxido de hidrogênio, composto potencialmente causador de dano celular por atuar negativamente sobre a membrana celular (SINHA; SAXENA, 2006). A perda da integridade de membranas reflete no extravasamento exacerbado de eletrólitos e na redução do vigor de sementes, conforme evidenciado pela redução dos valores de IVG (Figura 1b).

$\mathrm{O}$ índice de velocidade de germinação se ajustou à tendência quadrática e foi obtido com elevado coeficiente de determinação $\left(\mathrm{R}^{2}=0,95\right)$ atingindo a mínima resposta aos $-0,75 \mathrm{MPa}$. Houve redução do índice de velocidade de germinação ao tornar o potencial osmótico mais negativo, sendo observados resultados drásticos a partir de $-0,50 \mathrm{MPa}$ (Figura 1b). A diminuição deste índice se reporta a redução do número de sementes germinadas por dia, sendo indicativo da redução do vigor da semente.

$\mathrm{O}$ vigor consiste no conjunto de processos fisiológicos mediados por sinalizadores químicos e que envolvem a síntese, hidrólise, translocação e alocação de assimilados para o embrião, assim, qualquer fator biótico ou abiótico que afete a eficiência destes processos reflete negativamente no vigor da semente e da 
plântula (PESKE; VILLELA; MENEGHELLO, 2012). Neste contexto, cabe salientar que a adequada hidratação da semente durante a embebição é essencial para a reativação dos referidos processos metabólicos e para a retomada do crescimento do embrião e sua falta constitui um fator limitante ao processo germinativo (PESKE; VILLELA; MENEGHELLO, 2012).

O comprimento de órgãos foi alterado negativamente pelo potencial osmótico (Figura 1c) e colaborou para a redução da massa seca de órgãos (Figura 1d). Potenciais osmóticos mais baixos proporcionaram condição de meio que refletiu na tendência conjunta de redução do comprimento de parte aérea e de raiz, com pontos de mínima resposta em -0,75 MPa. Todavia, a resposta à restrição hídrica é variável entre genótipos, pois o déficit hídrico altera de forma distinta alguns parâmetros fisiológicos entre plantas tolerantes e sensíveis à falta de água (SILVA et al., 2007). A redução do crescimento pode ainda ser decorrente da diminuição da expansão celular, portanto, a diminuição da turgescência pode afetar negativamente o alongamento e a síntese de parede celular, resultando no menor desempenho de plântulas (ÁVILA et al., 2007).

A massa seca de parte aérea e de raiz apresentaram tendência à redução com o potencial osmótico, tendo os pontos de máxima, ocorrido em 0,0 e $-0,15 \mathrm{Mpa}$, respectivamente (Figura 1d). Resultados mais severos impostos pelo potencial osmótico sobre este atributo de crescimento foram observados a partir de $-0,50 \mathrm{MPa}$. O menor crescimento em comprimento e massa de plântulas é explicado pelo menor aproveitamento dos assimilados armazenados no endosperma, pela ineficiência de diferentes sistemas enzimáticos ou ainda pelo acúmulo de espécies reativas de oxigênio e pela peroxidação de lipídeos que refletem na perda da seletividade do sistema de membranas celulares (PESKE; VILLELA; MENEGHELLO, 2012).

$\mathrm{O}$ efeito da restrição hídrica observado sobre o desempenho de sementes e plântulas também influenciou de forma distinta a expressão isoenzimática. A isoenzima peroxidase alterou a expressão do número e a intensidade das bandas com o potencial osmótico da solução (Figura 2A). Tanto plântulas sob os potenciais de $-0,50$ quanto de $-0,75 \mathrm{MPa}$ apresentaram expressão da peroxidase, entretanto sob $-0,75 \mathrm{MPa}$, houve aumento no número e na intensidade das bandas. Rossi e Lima (2001) relatam que a indução na elevação da atividade da peroxidase pode ser mecanismo utilizado para a redução do nível de peróxido de hidrogênio, radical livre cujo acúmulo resulta na peroxidação de lipídeos, alterando a permeabilidade de membranas celulares. Desse modo, a elevação na expressão da peroxidase pode estar relacionada ao incremento da sua atividade devido à elevação da produção de radicais livres, ocasionada pela restrição hídrica. $\mathrm{O}$ acúmulo destes compostos potencialmente tóxicos pode ter ocasionado à perda de seletividade do sistema de membranas celulares, refletido negativamente na compartimentalização celular e afetando o a expressão do vigor de sementes (Figura 1b).

Por outro lado, a isoenzima malato-desidrogenase apresentou discreta intensificação das bandas a partir do potencial osmótico -0,25 MPa sem ocorrer alteração no número de bandas (Figura 2B). A enzima malato-desidrogenase é associada à biossíntese do oxalacetato pela interconversão do malato durante o ciclo dos ácidos tricarboxílicos, assume função importante na síntese de aminoácidos e na gliconeogenese, na manutenção dos potenciais redox e no intercâmbio de metabólitos entre o citosol e organelas. Além disso, é importante salientar que se constitui em importante enzima na respiração celular, assim, a maior expressão pode estar relacionada sua maior atividade e ao incremento da atividade respiratória em sementes em processo de perda de vigor no início da deterioração (SANTOS; MENEZES; VILLELA, 2005; PESKE; VILLELA; MENEGHELLO, 2012).

De maneira distinta das enzimas peroxidase e malato-desidrogenase, a isoenzima glutamato oxalacetato transaminase apresentou bandas mais intensas sob os menores potenciais osmóticos (Figura 2C). A maior expressão da enzima glutamato oxalacetato transaminase, em plântulas sob potenciais osmóticos mais baixos, está associada ao efeito estressante das referidas restrições hídricas sobre os órgãos do vegetal. A glutamato oxalacetato transaminase atua na oxidação de aminoácidos com vistas ao fornecimento de energia para o ciclo de Krebs ou para a redução do $\alpha$-cetoglutarato, voltada à biossíntese de novos aminoácidos destinados ao crescimento do embrião (MALONE et al., 2007). Logo, agentes estressantes que atuam direta ou indiretamente sobre esta enzima, podem afetar a retomada do crescimento do embrião (Figura 1a), a expressão do vigor de sementes (Figura 1b) e o crescimento inicial de plântulas (Figura 1d).

A expressão da isoenzima esterase foi alterada em plântulas sob potenciais osmóticos de $-0,50$ e $-0,75 \mathrm{MPa}$ (Figura 2D). Sob o potencial osmótico de $-0,50 \mathrm{MPa}$ houve expressão de menor número de bandas comparativamente às plântulas sob potencial osmótico de $-0,75 \mathrm{MPa}$, que foram mais intensas. A maior expressão da esterase em menores potenciais osmóticos mantém relação à redução do vigor de sementes, pois esta enzima está envolvida em reações de hidrólise de ésteres e estreitamente relacionada ao metabolismo de lipídios (SANTOS; MENEZES; VILLELA, 2005). A alteração no padrão de expressão da isoenzima esterase pode resultar em modificações no sistema de membranas celulares e refletir na redução do vigor e no desempenho de sementes e plântulas, conforme ao observado pela redução do índice de velocidade de germinação, da massa seca e do comprimento de parte aérea e de raiz (Figura 1c-d). A redução da expressão do vigor pode estar relacionada a problemas no processo respiratório, isto porque, para o adequado funcionamento das mitocôndrias e para a eficiente produção de energia da oxidação de compostos por meio da respiração, o sistema de membranas celulares necessita de rápido reparo e reorganização (PESKE; VILLELA; MENEGHELLO, 2012).

Quanto à isoenzima fosfatase ácida, a maior em intensidade de bandas ocorreu em plântulas sob os potencias osmóticos de 0,0 e $-0,25 \mathrm{MPa}$ (Figura 2D). A fosfatase ácida participa da hidrólise de ésteres, podendo atuar sobre o sistema de membranas celulares, afetar a atividade respiratória pela peroxidação de lipídios insaturados nas membranas mitocondriais e manter relação com o processo de deterioração em sementes. Segundo Camargo et al. (2000), a redução na atividade desta isoenzima pode afetar o nível de trifosfato de adenosina e o metabolismo do fosfato em sementes influenciando nos níveis de nucleotídeos, podendo assim, afetar o desempenho de sementes pela redução 
da quantidade de energia química disponível ao processo de retomada do crescimento (HENNING et al., 2010).

De maneira geral, restrições hídricas mais acentuadas reduziram a qualidade fisiológica de sementes e o desempenho de plântulas de centeio, bem como, exerceram influência sobre a expressão dos sistemas isoenzimáticos. Alterações na expressão isoenzimática ocasionadas pela restrição hídrica, podem ter refletido no pior desempenho das plântulas de centeio sob maiores potenciais hídricos, provavelmente pela perda de eficiência em diferentes processos fisiológicos em função da menor disponibilidade de água para hidrólise de assimilados e para a translocação de metabólitos destinados à retomada do crescimento do embrião.

Neste sentido, a hidrólise de substâncias de reserva e a síntese de aminoácidos podem ter sido influenciadas, bem como a reorganização do sistema de membranas celulares, afetando a síntese de novas proteínas e a produção de energia química (MALONE et al., 2007). Sendo assim, as variações na expressão isoenzimática podem estar relacionadas à alteração na sua atividade e com sensibilidade específica ao agente causador do estresse (VIEIRA et al., 2000), neste caso a restrição hídrica (HENNING et al., 2010).

\section{Conclusões}

O déficit hídrico, induzido por PEG-6000, afeta negativamente o desempenho de sementes e plântulas de centeio. Potenciais osmóticos inferiores a $-0,25 \mathrm{MPa}$ reduzem drasticamente a germinação, o vigor e o crescimento inicial de plântulas.

As isoenzimas glutamato oxalacetato transaminase e fosfatase ácida são mais sensíveis a partir do potencial de $-0,25 \mathrm{Mpa}$.

Potenciais osmóticos de $-0,5$ e $-0,75 \mathrm{MPa}$ aumentam a expressão das isoenzimas peroxidase, esterase e malato desidrogenase.

\section{Referências}

ALFENAS, A. C. Eletroforese de isoenzimas e proteínas afins: fundamentos e aplicações em plantas e microrganismos. Viçosa: UFV, 1998. 574 p.

ÁVILA, M. R. et al. Influência do estresse hídrico simulado com manitol na germinação de sementes e crescimento de plântulas de canola. Revista Brasileira de Sementes, Londrina, v. 29, n. 1, p. 98-106, 2007. http://dx.doi.org/10.1590/S0101-31222007000100014.

BRASIL. Ministério da Agricultura e Reforma Agrária. Regras para Análise de Sementes. Brasília: SNAD/CLAV, 2009. 398 p.

BRACCINI, A. L. et al. Influência do potencial hídrico induzido por polietilenoglicol na qualidade fisiológica de sementes de soja. Pesquisa Agropecuaria Brasileira, Rio de Janeiro, v. 33, n. 9, p. 1451-1459, 1998.

CAMARGO, M. L. P. et al. Atividade enzimática em plântulas de Eucalyptus grandis provenientes de sementes envelhecidas artificial e naturalmente. Ciência Florestal, Santa Maria, v. 10, n. 2, p. 113-122, 2000.

COMPANHIA NACIONAL DE ABASTECIMENTO - CONAB. Acompanhamento da safra brasileira de grãos 2015/16: décimo segundo levantamento. Brasília, 2016. Disponível: <http://www. conab.gov.br/OlalaCMS/uploads/arquivos/16_09_09_15_18_32_ boletim_12_setembro.pdf $>$. Acesso em: 05 fev. 2015
CUSTÓDIO, C. C.; SALOMÃO, G. R.; MACHADO NETO, N. B. Estresse hídrico na germinação e vigor de sementes de feijão submetidas à diferentes soluções osmóticas. Revista Ciência Agronômica, Ceará, v. 40, n. 4, p. 617-623, 2009.

DANTAS, C. V. S. et al. Influência da Sanidade e déficit hídrico na germinação de Sementes de Carthamus tinctorius L. Revista Brasileira de Sementes, Londrina, v. 33, n. 3, p. 574-582, 2011. http://dx.doi.org/10.1590/S0101-31222011000300020.

HENNING, F. A. et al. Composição química e mobilização de reservas em sementes de soja de alto e baixo vigor. Bragantia, Campinas, v. 69, n. 3 , p. $727-734,2010$.

KAPPES, C. et al. Germinação, vigor de sementes e crescimento de plântulas de milho sob condições de déficit hídrico. Scientia Agraria, Curitiba, v. 11, n. 2, p. 125-133, 2010.

LOPES, J. C.; MACEDO, C. M. P. Germinação de sementes de couve chinesa sob influência do teor de água, substrato e estresse salino. Revista Brasileira de Sementes, Brasília, v. 30, n. 3, p. 79-85, 2008. http://dx.doi.org/10.1590/S0101-31222008000300011.

MACHADO NETO, N. B. et al. Hydric stress induced by mannitol and sodium chloride in soybean cultivars. Brazilian Archives of Biology and Technology, Curitiba, v. 47, n. 4, p. 521-529, 2004. http://dx.doi.org/10.1590/S1516-89132004000400004.

MALONE, G. et al. Expressão diferencial de isoenzimas durante o processo de germinação de sementes de arroz em grandes profundidades de semeadura. Revista Brasileira de Sementes, Londrina, v. 29, n. 1, p. 61-67, 2007. http://dx.doi.org/10.1590/ S0101-31222007000100009.

MORAES, G. A. F.; MENEZES, N. L. Desempenho de sementes de soja sob condições diferentes de potencial osmótico. Ciência Rural, Santa Maria, v. 33, n. 2, p. 219-226, 2003. http://dx.doi. org/10.1590/S0103-84782003000200007.

MORAES, G. A. F.; MENEZES, N. L.; PASCUALI, L. L. Comportamento de feijão sob diferentes potenciais osmóticos. Ciência Rural, Santa Maria, v. 35, n. 4, p. 776-780, 2005. http://dx.doi.org/10.1590/ S0103-84782005000400004.

MOTERLE, L. M. et al. Germinação de sementes e crescimento de plântulas de cultivares de milho-pipoca submetidas ao estresse hídrico e salino. Revista Brasileira de Sementes, Londrina, v. 28, n. 3, p. 169-176, 2006. http://dx.doi.org/10.1590/S0101-31222006000300024.

NAKAGAWA, J. Testes de vigor baseados no desempenho das plântulas. In: KRZYZANOSWKI, F. C.; VIEIRA, R. D.; FRANÇA NETO, J. B. (Ed.). Vigor de sementes: conceitos e testes. Londrina: ABRATES, 1999. p. 2.1-2.24.

NAKAGAWA, J. Testes de vigor baseados na avaliação de plântulas. In: VIEIRA, R. D.; CARVALHO, M. (Ed.). Testes de vigor em sementes. Jaboticabal: FUNEP, 1994.

NOGUEIRA, R. J. M. C.; MORAES, J. A. P. V.; BURITY, H. A. Alterações na resistência à difusão de vapor das folhas e relações hídricas em aceroleira submetidas a déficit de água. Revista Brasileira de Fisiologia Vegetal, Campinas, v. 13, n. 1, p. 75-87, 2001. http:// dx.doi.org/10.1590/S0103-31312001000100009.

PESKE, S. T.; VILlELA, F. A.; MENEGHELlO, G. E. (Ed.). Sementes: fundamentos científicos e tecnológicos. 3. ed. Pelotas: UFPel, 2012. 573p.

ROSSI, C.; LIMA, G. P. P. Cádmio e a atividade de peroxidase durante a germinação de sementes de feijoeiro. Scientia Agricola, Piracicaba, v. 1, n. 58, p. 197-199, 2001. http://dx.doi.org/10.1590/ S0103-90162001000100030. 
SANTOS, C. M. R.; MENEZES, N. L.; VILLELA, F. A. Modificações fisiológicas e bioquímicas em sementes de feijão no armazenamento. Revista Brasileira de Sementes, Londrina, v. 27, n. 1, p. 104-114, 2005. http://dx.doi.org/10.1590/S0101-31222005000100013.

SCANDÁLIOS, J. G. Genetic control of multiple molecular forms of enzymes in plants: a rewiew. Biochemical Genetics, New York, v. 3, n. 1, p. 37-79, 1969.

SILVA, J. B.; RODRIGUES, T. J. D.; VIEIRA, R. D. Desempenho de sementes de soja submetida a diferentes potenciais osmóticos em polietilenoglicol. Ciência Rural, Santa Maria, v. 36, n. 23, p. 16341637, 2006. http://dx.doi.org/10.1590/S0103-84782006000500047.
SILVA, M. A. et al. Use of physiological parameters as fast tools to screen for drought tolerance in sugarcane. Brazilian Journal of Plant Physiology, Londrina, v. 19, n. 3, p. 193-201, 2007. http:// dx.doi.org/10.1590/S1677-04202007000300003.

SINHA, S.; SAXENA, R. Effect of iron on lipid peroxidation, and enzymatic and nonenzymatic antioxidants and bacoside-a content in medicinal plant Bacopa monnieri L. Chemosphere, Oxford, v. 62 , n. 8 , p. $1340-1350,2006$. http://dx.doi.org/10.1016/j. chemosphere.2005.07.030.

VIEIRA, A. R. et al. Alterações fisiológicas e enzimáticas em sementes dormentes de arroz armazenadas em diferentes ambientes. Revista Brasileira de Sementes, Londrina, v. 22, n. 2, p. 53-61, 2000. 